being run without benefit of this rubric, as is the worldwide patent system.

The allusion in your Feature to Paul Chu and the 1:2:3 superconductor paper — the contents of which had clearly reached rival research groups before publication, and in which "ytterbium" was changed to "yttrium" at the last minute points to but one of the very minor ineradicable defects of the peer-review system, that we can confirm. At the time that paper was submitted, several of its authors, including one of us (J. R. A.) who had made the very first samples of 1:2:3 at the University of Alabama, had a conversation with his Alabama colleagues and Dr Chu of the University of Houston, at which the wise decision was made to substitute $\mathrm{Yb}$ for $Y$ in the text. The galley proof ( still in J.R.A.'s possession) shows $\mathrm{Yb}$, not $\mathrm{Y}$, in all four places where it appears. The full chemical name of ytterbium — and, subsequently, yttrium - was conveniently omitted from the text of the paper so that the amendments before final printing could be confined only to the symbols. This stratagem was also alluded to in the Materials Research Society videotapes on the history of the 1:2:3 discovery, organized by one of us (R.R.). Everyone except the true believers knows that it is your nearest competitors (adversaries?) who often 'peer' review your paper. Hence, you must protect yourself by this and other subterfuges, like proposing work you have just completed.

Yet this is but a minor defect in the peer-review system. The enormous waste of scientists' time, and the absolute, ineluctable bias against innovation, are its worst offences.

'Review by competitors' is an all-tooaccurate description of this system, wreaking devastation on papers and proposals in science. Financial and selfinterest disclosures, such as competing for the same funds, should surely now be required of peers.

More: where is the evidence for any benefits from peer review? Recently, Nature (Nature 412, 751; 2001) and most medical journals have been forced to require financial disclosures by authors to deal with the fact that peer review could do nothing to avoid the widely acknowledged contamination of the literature. This was illustrated by papers published about the drugs Vioxx and Celebrex - just one example picked up by the secular press (Washington Post, 5 August 2001; Wall Street Journal, 22 August 2001) in frontpage stories after a paper in the Journal of the American Medical Association (J. Am. Med. Assoc. 286, 8; 2001) reported that these popular painkillers carried a risk of cardiovascular problems. The newspapers reported that cardiovascular risks from
Celebrex had been simply "omitted" from an earlier paper (J. Am. Med. Assoc. 284, $10 ; 2000)$. All sixteen authors of the earlier paper — including faculty from eight universities - were either employees, funded by or consultants of the manufacturers. What use was peer review here?

Finally, Nature should not repeat the old canards such as: "despite the problems thrown up by peer review, no serious alternative has yet been proposed". Nonsense. They have not only been proposed but have been in regular use worldwide for a very long time. The users include the world's largest research agency, the US Department of Defense, and industrial research worldwide.

Rustum Roy*, James R. Ashburn $\dagger$

${ }^{*}$ The Pennsylvania State University, 102 Materials Research Laboratory, University Park, Pennsylvania 16802, USA

†Elmco, 60 Technology Drive, Building 1, Suite N, Huntsville, Alabama 35805, USA

\section{Carrots, not sticks, give best 'quality assurance'}

Sir - I was interested in your News story "Proposed scheme will scrutinize student supervisors" (Nature 413, 761; 2001) describing the plans by the Biotechnology and Biological Sciences Research Council (BBSRC) and the Higher Education Funding Council for England (HEFCE) to improve training and standards for the supervisors of postgraduate students in the United Kingdom.

Raising the standards for postgraduate student supervision is a good thing. However, the rush by government and other higher-education bodies to introduce 'quality assurance' wherever conceivable, with initiatives such as the Research Assessment Exercise and the Institute for Learning and Teaching, appears little more effective in alleviating the real problems than sticking a plaster over a gangrenous wound.

The acknowledged difficulty in enrolling well-qualified postgraduate students in the United Kingdom — and the reason so many $\mathrm{PhDs}$ do not seek employment in their subjects - probably stems from the lack of an equitable career structure in higher education. I cannot think of another career where the most experienced practical practitioners, postdocs, live from short-term contract to short-term contract and risk being priced out of the job market when they have acquired years of experience.

This situation needs to be urgently remedied. Introduce a nationally recognized training scheme which allows research trainees to build a recognized skills portfolio. This would help them secure jobs as they progress through their career - even if this means reducing the number of $\mathrm{PhD}$ places. Training could include skills such as grant writing, staff management, project management and writing papers, in addition to traditional technical hands-on abilities.

Even when postdoctoral trainees do manage to get academic positions, they find that, since the late seventies, academic salaries have fallen far below those of comparable professions and of the private sector. Students graduating with an undergraduate degree and saddled with debts of, on average, $\mathfrak{E} 16,000$ (US\$22,600) are hardly likely to consider further years of penury and job insecurity worth the risk. Unless the government has the foresight to address these overarching problems, the future of the higher education sector and the intellectual skills base of the United Kingdom looks bleak. In the end you get the system that you pay for.

It would also be of help if carrots were used instead of sticks. How about HEFCE giving a pay rise to staff who do meet their new training standards? I would also be intrigued to know if this new spirit of 'above-board correctness' extends to paying realistic fees for external examiners of $\mathrm{PhD}$ theses. Currently the average fee is $\mathfrak{E} 120$ to examine a $\mathrm{PhD}$ thesis; the Association of University Teachers recommends a fee of $\mathfrak{E} 450$, which is not unreasonable. Try asking a management consultant to read about 250 pages, consult libraries and travel to crossexamine someone for this fee. The last time that I heard of an external examiner asking for $\mathfrak{E} 450$, the candidate's supervisor was told to find another examiner who would accept the lower fee.

\section{Roddie McKenzie}

Department of Dermatology, University of Edinburgh, Lauriston Building RIE, Edinburgh EH3 9YW, Scotland, UK

\section{Motion and meaning}

Sir - In his News and Views Feature

"Where drunkards hang out" (Nature 413, 686-687; 2001), Ian Stewart states

"Brownian motion is no longer important in its original physical context". I beg to differ. Analysis of diffusion as brownian motion is central to understanding the physics of diffusion-controlled biochemical reactions, such as ion permeation through protein channels, to take one example.

\section{Eric Jakobsson}

Department of Molecular and Integrative Physiology, National Center for Supercomputing Applications, University of Illinois, Urbana,

Illinois 61801, USA 